\title{
TITLE: A $\beta$ oligomers induce sex-selective differences in mGluR5 pharmacology and pathophysiological signaling in Alzheimer mice
}

\author{
Khaled S. Abd-Elrahman 1,2,6,\#, Awatif Albaker ${ }^{1,2,7, \#, ~ J e s s i c a ~ M . ~ d e ~ S o u z a ~}{ }^{1,2,8}$, Fabiola M. \\ Ribeiro $^{8}$, Michael G. Schlossmacher ${ }^{1,2,3,5}$, Mario Tiberi ${ }^{1,2,4,5}$, Alison Hamilton ${ }^{1,2, \$}$ \\ and Stephen S. G. Ferguson ${ }^{1,2, \$, *}$
}

${ }^{1}$ University of Ottawa Brain and Mind Institute, ${ }^{2}$ Departments of Cellular and Molecular Medicine,

${ }^{3}$ Medicine, ${ }^{4}$ Psychiatry, and the ${ }^{5}$ Ottawa Hospital Research Institute, University of Ottawa, Ottawa, Ontario, K1H 8M5, Canada.

${ }^{6}$ Department of Pharmacology and Toxicology, Faculty of Pharmacy, Alexandria University, Alexandria, 21521, Egypt.

${ }^{7}$ Department of Pharmacology and Toxicology, College of Pharmacy, King Saud University, Riyadh, 12371, Saudi Arabia

${ }^{8}$ Department of Biochemistry and Immunology, ICB, Universidade Federalde Minas Gerais, Belo Horizonte, Brazil.

\#These authors contributed equally

$\$$ Co-senior authors

ONE-SENTENCE SUMMARY: A $/ \mathrm{PrP}^{\mathrm{C}}$ complex binds to mGluR5 and activates its pathological signaling in male, but not female brain and therefore, mGluR5 does not contribute to the pathology in female Alzheimer's mice.

\section{*Corresponding author}

Dr. Stephen S. G. Ferguson

Department of Cellular and Molecular Medicine, University of Ottawa, 451 Smyth Dr. Ottawa, Ontario, Canada, K1H 8M5.

Tel: (613) 5625800 Ext 8889.

sferguso@uottawa.ca 


\section{ABSTRACT (250)}

Sex is a key modifier of the prevalence and progression of Alzheimer's disease (AD). $\beta$ Amyloid $(A \beta)$ deposition is a pathological hallmark of $A D$ and aberrant activation of metabotropic glutamate receptor 5 (mGluR5) by $A \beta$ has been linked to $A D$ progression. We find that mGluR5 exhibits distinct sex-dependent pharmacological profiles. Specifically, endogenous mGluR5 from male mouse cortex and hippocampus binds with high-affinity to $A \beta$ oligomers whereas, female mGluR5 exhibits no affinity to $A \beta$ oligomers. The binding affinity of mGluR5 to $A \beta$ oligomer is dependent on its interaction with cellular prion protein $\left(\mathrm{PrP}^{\mathrm{C}}\right)$ as mGluR5 co-immunoprecipitates with $\mathrm{PrP}^{\mathrm{C}}$ from male, but not female, mouse brain. $A \beta$ oligomers also bind with high-affinity to human mGluR5 in male, but not female, cortex. The mGluR5/Aß oligomer/PrP ${ }^{\mathrm{C}}$ ternary complex is essential to elicit mGluR5-dependent pathological signaling and as a consequence mGluR5-regulated GSK3ß/ZBTB16 autophagic signaling is dysregulated in male, but not female, primary neuronal cultures. These sex-specific differences in mGluR5 signaling translate into in vivo differences in mGluR5-dependent pathological signaling between male and female AD mice. We show that the chronic inhibition of mGluR5 using a mGluR5-selective negative allosteric modulator reactivates GSK3 $\beta / Z B T B 16$-regulated autophagy, mitigates $A \beta$ pathology and reverses cognitive decline in male, but not female, APPswe/PS1 $\triangle \mathrm{E} 9$ mice. Thus, it is evident that, unlike male brain, mGluR5 does not contribute to $A \beta$ pathology in female $A D$ mice. This study highlights the complexity of mGluR5 pharmacology and $A \beta$ oligomer-activated pathological signaling and emphasizes the need for clinical trials redesign and analysis of sex-tailored treatment for AD.

KEY WORDS: Alzheimer's disease, autophagy, mGluR5, sex, $\beta$-Amyloid, cellular prion protein 


\section{INTRODUCTION}

Alzheimer's disease $(A D)$ is a progressive neurodegenerative disease characterized by age-related memory loss and cognitive decline and despite the alarming prevalence, no available treatments exist to either modify or reverse its progression (1-3). $\beta$-Amyloid $(A \beta)$ oligomers and hyper-phosphorylated tau protein represent pathological hallmarks of $A D$ and accumulate with disease progression to disrupt neuronal signaling and trigger neurodegeneration (4-6). Sex is an important modulator of AD prevalence and both clinical and preclinical evidence indicate that the incidence in females is higher than age- and risk factor-matched males (7-10). This higher incidence of cognitive impairment is commonly attributed to reduced estrogen and/or estrogen receptors levels following menopause (11-13). However, this assumption was weakened by the first large-scale clinical study demonstrating increased risk of dementia and poor cognitive outcomes following hormone-replacement therapy (Women's Health Initiative Memory Study, WHIMS) $(14,15)$.

Glutamate, the main excitatory brain neurotransmitter, plays a key role in learning and memory and the $\mathrm{G}_{\mathrm{aq}}$-coupled metabotropic glutamate receptors 5 (mGluR5) is of particular interest in $A D$ pathology $(5,16)$. mGluR5 functions as an extracellular scaffold for $A \beta$ and cellular prion protein $\left(\mathrm{PrP}^{\mathrm{C}}\right)$ and the complex between $\mathrm{PrP}^{\mathrm{C}}$ and mGluR5 is essential for $\mathrm{A} \beta$ binding (1719). $\mathrm{A} \beta$ also promotes mGluR5 clustering, increases intracellular $\mathrm{Ca}^{2+}$ release and inhibits autophagy $(17,19,20)$. Moreover, the pharmacological and genetic silencing of mGluR5 reverses cognitive deficits and reduces $A \beta$ pathology in male $A D$ rodent models (20-24). While these studies emphasized the key role of mGluR5 in AD pathophysiology, it is not yet clear whether alterations in mGluR5 signaling are conserved between male and female AD models. Given that both clinical and experimental evidence indicate a divergent AD pathology between males and female, the dramatic drug treatment failure rate in $A D$ clinical trials warrant a better delineation of the molecular signaling mechanism(s) underlying sex-related pathophysiological differences in 
AD $(7,10)$. It is important to note that some previous studies have attempted to pharmacologically target mGluR5 in AD mice from both sexes but surprisingly the results were not stratified according to sex and therefore, an accurate representation for the contribution of pathological mGluR5 signaling to $A D$ in females cannot be reached $(25,26)$.

Our rationale was to assess whether mGluR5 differentially contributes to pathology in both sexes and therefore, we evaluated the binding affinity of $A \beta$ to mGluR5 and the efficacy of $A \beta$ in triggering pathological autophagic signaling in male and female AD mice. We also tested whether the mGluR5 orally bioavailable negative allosteric modulator (NAM), 2-chloro-4-((2,5-dimethyl-1(4-(trifluoromethoxy)phenyl)-1H-imidazol-4-yl)ethynyl) pyridine (CTEP) (27), differentially alters cognition and progression of $A \beta$ pathology between male and female APPswe/PS1 $\triangle E 9$ (APP) mice (28). It is worth noting that although other mGluR5 ligands have been reported to only either improve memory deficits (BMS-984923) or A $\beta$ pathological signaling (CDPPB), but not both, in AD mouse models $(25,26)$. Our choice of CTEP was based on its superior capabilities in reversing $A \beta$ pathology and improving cognitive function with no evidence of drug-related adverse outcomes after extended treatment regimens $(22,24)$.

Our findings indicate that $A \beta$ oligomers binds with high affinity to mGluR5 in both male mouse and human cortex, but exhibits no affinity for mGluR5 in either female mouse or human brain tissue. The binding of $A \beta$ oligomers to mGluR5 was $\mathrm{PrP}^{\mathrm{C}}$-dependent as mGluR5 coimmunoprecipitated with $\mathrm{PrP}^{\mathrm{C}}$ from male, but not female, mouse hippocampus. When wild-type male E18 embryonic neuronal cultures were treated with $A \beta$ oligomers, it inhibited one of the key mGluR5-regulated autophagic pathways, the GSK3 $\beta / Z B T B 16$ pathway. Specifically, A $\beta$ increased pS9-GSK3 $\beta$ phosphorylation and blocked ZBTB16-mediated autophagy in an mGluR5dependent manner. In contrast, the treatment of female cultures with A $\beta$ did not alter pS9-GSK3 $\beta$ phosphorylation and had no effect on autophagy. Our in vitro findings were translatable in vivo since treatment of male APP mice with mGluR5 NAM was associated with enhanced ZBTB16- 
regulated autophagy, reduced $A \beta$ pathology and improved cognitive function. However, CTEP exhibited no efficacy in female APP mice and rather caused cognitive impairment in wild-type female mice. These studies revealed that mGluR5 exhibits unexpected and distinct pharmacological profiles with respect to $A \beta$ oligomer/PrPC interactions in male and female brain that can dictate the relative contribution of mGluR5 to AD pathology and therapeutics between both sexes. 


\section{RESULTS}

\section{Sex-specific interaction of $A \beta$ oligomers and $\mathrm{PrP}^{\mathrm{C}}$ with mGluR5 in mouse brain}

$\mathrm{A} \beta$ oligomers binds with high affinity to the $\mathrm{PrP} / \mathrm{mGluR} 5$ complex and the $\mathrm{A} \beta$ oligomer/PrPC complex can then drive the pathological signaling of mGluR5 $(17,29)$. Therefore, we first tested whether the binding of $A \beta$ oligomers to endogenous mGluR5 is sex-specific. We assessed $A \beta$ oligomer-mediated displacement of radiolabeled mGluR5 antagonist (MPEP) binding to endogenously expressed mGluR5 in plasma membrane preparations from male and female wildtype mouse cortex and hippocampus. To our surprise, $A \beta$ oligomers effectively displaced $\left[{ }^{3} \mathrm{H}\right]-$ MPEP binding to male, but not female mouse cortical (Fig. $1 \mathrm{~A}$ and $1 \mathrm{~B}$ and Table1) and hippocampal membrane preparations (Fig. 1C and 1D and Table 1). The displacement of $\left[{ }^{3} \mathrm{H}\right]-$ MPEP binding by non-radioactive MPEP was not different when both sexes were compared in each brain regions (Fig. 1A-D and Table 1). Thus, $A \beta$ oligomers binding assays revealed for the first-time distinct sex-dependent pharmacological profiles for mGluR5.

Since $A \beta$ oligomers binding to mGluR5 is known to be dependent on the interaction of the receptor with $\operatorname{PrP}^{\mathrm{C}}(17,29-31)$, we tested whether $\operatorname{PrP}^{\mathrm{C}}$ interacts with mGluR5 in a sex-specific manner. We first confirmed that the size of the $A \beta$ oligomers that we employed in our study is capable of interacting with mGluR5/PrPC scaffold and that $\operatorname{PrP}^{\mathrm{C}}$ is key for $A \beta$ binding to mGluR5 by performing radioligand binding assays in $\mathrm{PrP}^{\mathrm{C}}$ null (CF10) cells transfected with mGluR5. In control experiments, we found that $A \beta$ oligomers did not displace $\left[{ }^{3} \mathrm{H}\right]-\mathrm{MPEP}$ binding in $\mathrm{CF} 10$ cells (Fig 2A), but that co-transfection of CF10 cells with $\mathrm{PrP}^{\mathrm{C}}$ restored the ability of $\mathrm{A} \beta$ oligomer to bind mGluR5 (Fig. 2B). We then tested whether $\mathrm{PrP}^{\mathrm{C}}$ binding to mGluR5 was different between both sexes and found that mGluR5 co-immunoprecipitated with $\mathrm{PrP}^{\mathrm{C}}$ from male, but not female, wildtype mouse hippocampal tissue (Fig. 2C). Binding specificity of $\mathrm{PrP}^{\mathrm{C}}$ antibody to mGluR5 was validated by the lack of receptor immunoprecipitation in hippocampus from $\mathrm{mGluR} 5^{-/-}$mice. 
Overall, our findings indicated that, unlike what was observed for males, the mGluR5/ $A \beta$ oligomer/PrPC ternary complex is not formed in female mouse brain.

\section{Sex-specific binding of $A \beta$ oligomers to mGluR5 in human cortex}

To validate that sex-specific binding of $A \beta$ to mGluR5 was not exclusive to mouse tissues, we performed [ $\left.{ }^{3} \mathrm{H}\right]-$ MPEP binding displacement assays in cortical membranes prepared from male and female human cortical brain samples obtained at autopsy. Identical to what was observed for mouse cortical membranes, displacement of $\left[{ }^{3} \mathrm{H}\right]$-MPEP binding by MPEP was not significantly different between male and female human cortical membranes (Fig. 3A and 3B and Table 1). However, $A \beta$ oligomers only displaced $\left[{ }^{3} \mathrm{H}\right]$-MPEP binding to male membranes (Fig. $3 \mathrm{~A}$ and $3 \mathrm{~B}$ and Table 1) suggesting that the differential binding of $A \beta$ oligomers to mGluR5 between males and females is an evolutionally-conserved phenomenon and may indeed contribute to genderspecific pathophysiology in human AD patients.

\section{Sex-specific Aß-activated mGluR5 signaling in primary embryonic neuronal cultures}

Since $A \beta$ oligomers binding to mGluR5 was shown to induce receptor clustering and activate its pathological signaling $(17,19)$, we tested whether $A \beta$ oligomer binding to mGluR5 could inactivate GSK3ß/ZBTB16 autophagy pathway, which we identified to be engaged downstream of mGluR5, in a sex-specific manner in the absence of sex hormones in the media. The GSK3 $\beta / Z B T B 16$ pathway was one of the mGluR5 autophagic signaling mechanisms that was previously observed to be dysregulated in male AD mouse models and correlated with a loss of clearance of $A \beta(20,24,32)$. Thus, to avoid potentially confounding influence of sex hormones on mGluR5 signaling, we examined $A \beta$-evoked signaling in primary wild-type male and female E18 mouse cortical neurons in cell culture. Sex of the cultures was determined by PCR amplification to detect $\mathrm{X}$ chromosome-linked $\mathrm{Rbm31}$ gene relative to its divergent $\mathrm{Y}$ chromosome gametolog (33) (Fig. 4A). Treatment of male cultures with $A \beta$ oligomers (100 nM) induced pS9- 
GSK3 $\beta$ phosphorylation, increased ZBTB16 expression and inhibited autophagy as measured by elevated p62 expression in a manner that was inhibited by CTEP (10 $\mu \mathrm{M})$ (Fig. 4B). These changes were not observed in cultures derived from female embryos (Fig. 4B). These results clearly demonstrated that $\mathrm{A} \beta$ oligomers inactivated ZBTB16 autophagic signaling in male, but not female, neurons in a sex hormone-independent, but mGluR5-dependent manner.

\section{mGluR5 inhibition reduced AD-related pathology in male, but not female, APP mice}

We determined whether the differences in mGluR5-regulated GSK3 $\beta / Z B T B 16$ signaling between male and female cultured neurons after exposure to $A \beta$ oligomers were translatable in vivo. To test this, 6 month old male and female wild-type and APP mice were treated with vehicle or CTEP $(2 \mathrm{mg} / \mathrm{Kg})$ for 12 weeks and brains were harvested at the end of treatment for biochemical and immunohistochemical assessments. We chose the APP model as both male and female mice exhibited a robust $A \beta$ accumulation and cognitive impairment by 9 months $(28,34)$ and this treatment regime was effective in improving memory deficits and reversing $A \beta$ pathology in 12-month-old male APP mice (22). Here, we found that cell signaling mediators of the GSK3ß/ZBTB16/ATG14 autophagic pathway were inhibited in male APP mice. Specifically, we detected an increased pS9-GSK3 $\beta$ level, increased ZBTB16 expression, reduced ATG14 expression and the accumulation of p62 protein (Fig. 5A-D) $(20,32,35)$. CTEP treatment of male APP mice attenuated pS9-GSK3 $\beta$ phosphorylation, reduced ZBTB16 protein expression, increased ATG14 protein expression resulting in a loss of p62 protein (Fig. 5A-D). When the same experiments were performed in female APP mice no alterations in GSK3ß/ZBTB16/ATG14 signaling were observed in vehicle-treated female APP mice and as a consequence CTEP treatment had no discernable effect in on GSK3ß/ZBTB16/ATG14 pathway in either wild-type or APP female mice (Fig. 5A-D).

We then tested whether the sex-specific effect of CTEP on GSK3ß/ZBTB16/ATG14 signaling in APP mice was correlated with a similar change in A $\beta$ pathology. We found that the 
deposition of $A \beta$ plaque density was significantly reduced in male APP mice following the CTEP treatment regime, whereas A $\beta$ plaque density in either the hippocampus or cortex of female APP animals were not changed in response to CTEP treatment (Fig. 5E and 5F). Soluble A $\beta$ levels detected in brain lysates from both vehicle-treated male and female APP mice were comparably increased versus sex-matched wild-type mice (Fig. 5G). CTEP treatment of male APP mice resulted in significantly reduced soluble $A \beta$ levels, whereas it did not change soluble $A \beta$ levels in female APP mice (Fig. 5G). Overall, these findings show that, while $A \beta$ oligomers contribute to AD-like neuropathology in both sexes of APP mice, the A $\beta$ oligomer-mediated antagonism of a mGluR5-regulated GSK3 $\beta / Z B T B 16$ autophagy contributing to $A \beta$ pathology was exclusive to male mice. This may explain why mGluR5 inhibition reduced $A \beta$ deposition in male APP mice only.

\section{mGluR5 blockade improved cognitive deficits in male, but not female, APP mice}

We finally tested whether sex-specific outcomes of CTEP treatment on A $\beta$ pathology were reflected on the memory function of APP mice. Vehicle and CTEP-treated male and female wildtype and APP mice were tested for impairments in working and spatial memory in the novel object recognition test and the Morris water maze (MWM) and Morris water maze with reversal (RMWM). In the novel object recognition test, vehicle-treated wild-type male and female mice discriminated between novel and familiar objects, whereas vehicle-treated male and female APP mice failed to discriminate between objects (Fig. 6A and 6B). Following CTEP treatment, male APP mice regained the capacity to discriminate between objects, whereas female APP mice remained cognitively impaired (Fig. 6A and 6B). In MWM and RMWM, vehicle-treated male and female APP mice exhibited significantly longer escape latencies and less time spent in target quadrant than did similarly treated same sex wild-type mice (Fig.7A-D). CTEP treatment improved male APP mice performance in both the MWM and RMWM as measured by shorter escape latency and longer time spent in target quadrant with values indistinguishable from wild-type mice (Fig. 7A-D). In contrast, when compared to vehicle-treated female APP mice, CTEP treatment did not improve 
either escape latency or time spent in target quadrant of female APP mice in either the MWM or RMWM (Fig. 7A-D). Unlike what we observed for wild-type male mice, CTEP treatment impaired female wild-type mouse performance in the RMWM compared to vehicle-treated wild-type mice, with the mice showing impaired escape latencies and reduced time spent in the target quadrant (Fig. 7C and 7D). Taken together, it is evident that male and female APP mice presented with comparable cognitive impairments and similar $A \beta$ burdens, but the chronic inhibition of mGluR5 mitigated AD-like neuropathology in male, but not female, mice. These findings provide in vivo evidence for the sex-specific contribution of mGluR5 to AD pathophysiology and corroborate our primary neuronal cultures findings. 


\section{DISCUSSION}

One major challenge in AD therapy is the identification of a pharmaceutical target that both manages disease symptomology and modifies disease progression. Genetic and pharmacological silencing of mGluR5 has identified a contributory role for mGluR5 in A $\beta$-related cognitive decline and pathology in male $A D$ mice $(21,22)$. However, gender-specific responses to therapies have been reported in many neurological diseases including AD which have the potential to further complicate the process of drug discovery $(7,8,10)$ and therefore, delineation of sex-specific differences in AD pathophysiology became essential. We show here that, unlike what is observed for mGluR5 expressed in male tissue, mGluR5 is incapable of scaffolding either A $\beta$ oligomers or $\mathrm{PrP}^{\mathrm{C}}$ in female mouse brain tissue to elicit pathological mGluR5 signaling. This failure to form a mGluR5-scaffolded complex is conserved in both mouse and human female cortical tissue and represents an unexpected, but novel sex-specific regulation of mGluR5 pharmacology and signaling that appears to be evolutionarily conserved. The sex-dependent contribution of mGluR5 to $A D$ pathology was then validated in vivo since treatment of APP mice with a mGluR5 NAM improved cognitive deficits and reduced $A \beta$-related pathology in males, but was ineffective in females despite a comparable disease phenotype. This study has major implications as it shows how GPCRs, the most common class of receptors targeted by prescription drugs (36), can exhibits district gender-specific pharmacological profiles that must be considered during the process of drug development. Moreover, it highlights the need for sex-specific stratification of neurodegenerative drug trial results that will impact the guidance of future design of sex-tailored treatment strategies.

The ability of $\mathrm{PrP}^{\mathrm{C}}$ and $\mathrm{A} \beta$ oligomers to form a scaffolding complex with male mGluR5 can promote receptor clustering at the synapses $(17,19)$ and prevent the constitutive receptor endocytosis (37) is crucial in activating the pathological signaling of mGluR5 $(5,38)$. One of the consequences of pathological mGluR5 activation by $A \beta$ is the inhibition of autophagy flux $(20,24)$ 
that can then trigger a feedforward mechanism leading to further accumulation of $A \beta$ oligomers and exacerbation of glutamatergic excitotoxicity. mGluR5 NAM via its binding to the allosteric site of mGluR5, may disrupt the interaction between $A \beta$ oligomers and the receptor and consequently interrupt receptor-activated neurodegeneration. In fact, we have previously reported that mGluR5 NAM treatment normalizes the increased cell surface expression and signaling of mGluR5 in male APP mice (20). The lack of $\mathrm{PrP}^{\mathrm{C}} / \mathrm{A} \beta$ oligomer binding to female mGluR5 means that this feedforward mechanism cannot be initiated by mGluR5 and therefore nullify the contribution of mGluR5 to AD pathophysiology in female AD mice and explains the lack of mGluR5 NAM efficacy in female mice.

$A \beta$ oligomers represent a normal proteolytic byproduct of amyloid precursor protein metabolism and are normally found at low levels in the brain. Alterations in the production and/or clearance of $A \beta$ oligomers can shift the homeostasis towards increased cellular $A \beta$ oligomer levels and accelerate neurodegeneration $(4,39)$. Therefore, enormous effort has been directed toward identifying novel pathways that can regulate $A \beta$ oligomer accumulation. Within this context, autophagy represents an essential protein degradation pathway and defects in autophagy were reported in the early stages of $A D$ in both animal models and patients (40-44). We find that mGluR5 triggers pathological inhibition of autophagy via a ZBTB16-Cullin3-Roc1 E3-ubiquitin ligase pathway (35) in male, but not female, APP mice. The antagonism of mGluR5 was associated with improved cognitive function and reduced A $\beta$ pathology in male APP mice, but unfortunately this improvement was not observed in female mice.

We and others have previously reported that both mGluR5 negative and silent allosteric modulators improve cognitive function in male APP mice, but only NAMs reduce A $\beta$ oligomerrelated pathology $(22,25)$. This combined data suggests the possibility of repurposing mGluR5 selective modulators for treatment of male AD patients. This is of particular interest since the mGluR5 NAM basimglurant has been shown to be well-tolerated by patients in clinical studies for 
Fragile X mental retardation and major depressive disorder (45, 46). However, a critical drawback for repurposing mGluR5 selective drugs to treat $A D$ in the general population is that mGluR5 fails to interact with $A \beta$ oligomers in female tissue and therefore, mGluR5 contribution to cognitive decline and $A D$ pathology in females is not significant and must be mediated by alternative mechanism(s). Nevertheless, important opportunities still exist for the treatment of AD in men by mGluR5-selective drugs.

Our a priori expectation predicted that mGluR5 antagonism would be equally effective in both males and females, as there have been no reported differences in either gene editing or genomic regulation of male versus female mGluR5 expression, subcellular localization and/or function. Thus, one of the major challenges of $A D$ research remains understanding the underlying pharmacological and physiological differences in the manifestation of AD pathology in males versus females, in both animal $A D$ mice and human patients. The sex-dependent regulation of the formation of the mGluR5/A $\beta$ oligomer/PrPC complex is clearly one of the underlying mechanisms for why mGluR5 antagonism is not effective in the treatment of cognitive impairment and $A \beta$ pathology in female mice. However, this leaves open the question as to what is the underlying biological reason for why mGluR5 exhibits differential pharmacological properties in neurons of both sexes. Metabotropic glutamate receptors are allosterically regulated receptors and thus their pharmacological function may be regulated by differential interactions with either intra- or extracellular regulatory proteins in male and female animals $(16,47)$. Moreover, we cannot rule out sex-specific difference in either mGluR5 variant splicing or interactomes that may influence its binding to other extracellular scaffolds such as $\operatorname{PrP}^{C}$ and $A \beta$.

The pharmacology underlying disease etiology and progression regulated by cellular processes that are independent of mGluR5 in females remains to be determined. The important underlying message from the current study is that mGluR5 is not a contributor to disease progression and pathology in female mice, thereby severely limiting the use of mGluR5 
antagonists in women. However, it is important to acknowledge that mGluR5 is not the only cell surface target for $A \beta$ oligomers and a multicity of different targets can contribute to sex-dependent and -independent changes in synaptic signaling, synaptic pruning, autophagy and neuronal cell death in female $A D$ (48). Since we detect impairment in autophagy flux in female AD mice, it will be also important to explore specific alterations in the other autophagic signaling mechanism(s) in female $A D$ brain and identify novel approaches to effectively target them. More so, given the role of mGluR5 in synaptic function $(5,49)$ and the poor cognitive performance of mGluR5 NAMtreated control female mice, it will be essential to exploit other aspects of altered mGluR5 synaptic signaling in female brain.

In summary, we report that sex-specific differences in mGluR5 pharmacology observed in mouse cortical tissue are mirrored in human cortex and show that mGluR5 antagonism reduces cognitive impairment and $A \beta$ pathology in male, but not female, $A D$ mice. Our data clearly demonstrates that mGluR5 does not represent an effective pharmacological target for the treatment of $A D$ in women, but that it still remains a potentially effective target for the treatment of the early stages of $A D$ in men. This study highlights the need for the sexual stratification of neurodegenerative drug trial result to aid in the development of sex-specific therapeutic strategies. 


\section{MATERIALS AND METHODS}

Reagents: CTEP (1972) was purchased from Axon Medchem. $\beta$-Amyloid [1 42] PTD Human protein (03111), Amyloid beta (Aggregated) Human ELISA Kit (KHB3491), Sulfo-NHS-SS-Biotin (21331), NeutrAvidin Resins (29200), goat anti-Rabbit (G-21234) and anti-mouse (G21040) IgG $(\mathrm{H}+\mathrm{L})$ Cross-Adsorbed HRP Secondary Antibody, rabbit anti- $\beta$-Amyloid (71-5800) and rabbit anti$\beta$-Actin (PA1-183) were from Thermo Fisher Scientific. Rabbit anti- pS9-GSK3 $\beta$ (9323) and mouse anti-GSK3 $\beta$ (9832) antibodies were from Cell Signaling Technology. Rabbit anti-ATG14L (PD026) was from MBL International. Immunoprecipitation kit (206996), mouse anti-P62 (56416), rabbit anti-vinculin (129002) and rabbit anti-ZBTB16 (39354) were from Abcam. Rabbit anti-mGluR5 (AB5675) was from Millipore. Mouse Anti-Prion Protein $\left(\operatorname{PrP}^{\mathrm{C}}\right)$ Clone SAF-32 (189720-1) was from Cayman Chemical. $\left[{ }^{3} \mathrm{H}\right]$ MPEP (VT237) was from Vitrax, MPEP (1212) was from Tocris, Effectene Transfection reagent (301425) was from Qiagen and VECTASTAIN Elite ABC HRP Kit (Rabbit IgG, PK-6101) was from Vector Laboratories. Reagents used for western blotting were purchased from Bio-Rad and all other biochemical reagents were from Sigma-Aldrich.

Animals: Mice were obtained from The Jackson laboratories and bred to establish littermate controlled female and male wild-type (C57BL/6J, stock\# 000664), APPswe/PS1 $\Delta$ E9 (B6C3-Tg (APPswe/PSEN1 $\triangle E$ 9)85Dbo/J, stock\# 34829) and mGluR5-- (B6;129-Grm5tm1Rod/J, stock\# 003121 ) that were group-housed in cages of 2 or more animals, received food and water ad libitum and maintained on a 12 -hour light/12hour dark cycle at $24^{\circ} \mathrm{C}$. Groups of 24 male and female Wt and APPswe/PS1 $\triangle E 9$ mice were aged to 6 months of age and 12 mice from each group were randomized and blindly-treated every $48 \mathrm{~h}$ based on weekly weights with either vehicle (DMSO in chocolate pudding) or CTEP (2 mg/kg, dissolved in 10\% DMSO then mixed with chocolate pudding, final DMSO concentration was $0.1 \%)$ for 12 weeks $(22,32)$. Cognitive function of all animals was assessed prior to and following 12 weeks of drug treatment. At the end of the 12week treatment, mice were sacrificed by exsanguination and brains were collected and 
randomized for biochemical determinations and immunostaining. Mice used for radioligand binding and coimmunoprecipitation experiments were 3-month-old Wt. All animal experimental protocols were approved by the University of Ottawa Institutional Animal Care Committee and were in accordance with the Canadian Council of Animal Care guidelines.

Human specimens: All tissues were obtained collected after consent was provided from patients or the next kin in accordance with institutional review board-approved guidelines. Frozen samples of cortices from subjects under 50 years of age were acquired through the University of Alabama and the Autism Tissue Program. Additional, frozen specimens from adults above age 60 years were obtained from the Neuropathology Service at Brigham and Women's Hospital and the Department of Pathology and Laboratory Medicine at The Ottawa Hospital. Patients' gender, age and diagnosis were as follow: male, 34-year-old, vasculitis/encephalitis; male, 70-year-old, dementia with lewy bodies; male, 65-year-old, dementia with lewy bodies; male, 75-year-old, healthy; female, 44-year-old, carcinoma; female, 55-year-old, healthy; female, 65-year-old, healthy; female, 73-year-old, healthy.

Cell lines: CF10 cells were maintained in Opti-MEM supplemented with FBS (10\% v/v), respectively at $37^{\circ} \mathrm{C}$ in $5 \% \mathrm{CO}_{2}$ humidified incubator. CF10 cells were transfected with FLAGmGluR5 $\pm \mathrm{PrP}^{\mathrm{C}}$ using Effectene transfection reagents following the manufacture's protocol.

Primary neuronal culture: Cultures were prepared from the cortical region of E18 male and female wild-type embryo brains. Briefly, cortical tissue of each mouse embryo was trypsindigested followed by cell dissociation using a fire-polished Pasteur pipette. Cells were plated on Poly-L-Ornithine-coated dishes in neurobasal medium supplemented with N2 and B27 supplements, $2.0 \mathrm{mM}$ GlutaMAX, $50 \mu \mathrm{g} / \mathrm{ml}$ penicillin, and $50 \mu \mathrm{g} / \mathrm{ml}$ streptomycin. Cells were maintained for 12 to 15 days at $37^{\circ} \mathrm{C}$ in $5 \% \mathrm{CO}_{2}$ humidified incubator before experimentation. 


\section{Experimental Methods}

\section{Novel object recognition}

Mice were habituated in the testing room for 30 mins and testing was blindly performed during the animal's light cycle. Mice were placed in the empty box measuring $45 \times 45 \times 45 \mathrm{~cm}$ for $5 \mathrm{~min}$ and 5 min later, 2 identical objects were placed in the box $5 \mathrm{~cm}$ from the edge and $5 \mathrm{~cm}$ apart. Mice were returned to the box for $5 \mathrm{~min}$, and allowed to explore, as described previously (32). Time spent exploring each object was recorded using a camera fed to a computer in a separate room and analyzed using Noldus Ethovision 10 software. Mice were considered to be exploring an object if their snout was within $1 \mathrm{~cm}$ of the object. Each experiment was repeated 24 hours after first exposure with one object replaced with a novel object. Data was interpreted using recognition index which was as follows: time spent exploring the familiar object or the novel object over the total time spent exploring both objects multiplied by 100 , and was used to measure recognition memory $(T A \text { or } T B /(T A+T B))^{\star} 100$, where $T$ represents time, $A$ represents familiar object and B, novel object.

\section{Morris water maze (MWM) and reversal Morris water maze (RMWM)}

Animals were habituated in the testing room for $30 \mathrm{~min}$ and testing was blindly performed during the animal's light cycle. The Morris water maze test was performed in a white opaque plastic pool (120 cm in diameter), filled with water and maintained at $25^{\circ} \mathrm{C}$ to prevent hypothermia, as described previously (22). A clear escape platform (10 cm diameter) was placed $25 \mathrm{~cm}$ from the perimeter, hidden one $\mathrm{cm}$ beneath the surface of the water. Visual cues were placed on the walls in the room of the maze as spatial references. Mice were trained for 4 days (four trials per day and 15 mins between trails) to find the submerged platform at a fixed position from a random start point of the 4 equally spaced points around the pool. Each trial lasted either 60 seconds or until the mouse found the platform and mice remained on the platform for 15 seconds before being 
removed to their home cage. If the mice failed to find the platform within 60 seconds, they were guided to the platform by the experimenter. Escape latency was measured using Ethovision 10 automated video tracking software from Noldus. On day 5, the probe trial (a single trial of 60 seconds) was performed by removing the platform and allowing the mice to swim freely in the pool and recording the time spent in the target quadrant. RMWM task was initiated 24 hours after completion of MWM using the same paradigm as MWM, with 4 days acquisition and probe trial. In the RMWM task, the platform was relocated to a new position.

\section{Sandwich ELISA for A $\beta$ oligomer levels}

ELISA was performed as described previously $(22,24)$. Briefly, brains were dissected and one hemisphere was used to analyze oligomeric $A \beta$ levels. Brain homogenates were divided and centrifuged at $4^{\circ} \mathrm{C}$ at $100,000 \times \mathrm{g}$ for 1 hour. The supernatant was then diluted 1:10 with kitprovided buffer before carrying out the ELISA, which was performed in triplicate and measured as detailed in the manufacturer's protocol. Protein concentrations were quantified using the Bradford protein assay (Bio-Rad). The final $A \beta$ concentrations were determined following normalization to total protein levels.

\section{$\beta$-Amyloid immunohistochemistry}

Immunostaining was performed as described previously $(22,24)$. Briefly, brains were coronally sectioned through the cortex and hippocampus and staining was performed on $40 \mu \mathrm{m}$ free-floating sections using a peroxidase-based immunostaining protocol (VECTASTAIN Elite ABC HRP Kit). Sections were incubated overnight in primary antibody for $A \beta(1: 200)$ at $4{ }^{\circ} \mathrm{C}$, washed, incubated in biotinylated antibody (biotinylated horse anti-rabbit, 1:400) for 90 mins at 4 ${ }^{\circ} \mathrm{C}$, then incubated in an avidin biotin enzyme reagent for 90 min at $4^{\circ} \mathrm{C}$ and visualized using a chromogen. Sections were mounted on slides and visualized with a Zeiss AxioObserver epifluorescent microscope with a Zeiss $20 \times$ lens, using representative $900 \mu^{2}$ areas of cortex 
and hippocampus. Experimenters were blinded to drugging and analysis. Six to eight sections per mouse were analyzed and for each section 5 ROls were analyzed in the cortex and 2 ROls in the hippocampus using the cell counter tool in Image $\mathrm{J}$ (50). This number of ROIs prevents the selection of only densely stained regions.

\section{Immunoblotting}

A brain hemisphere or neuronal culture dish was lysed in ice-cold lysis buffer (50 mM Tris,

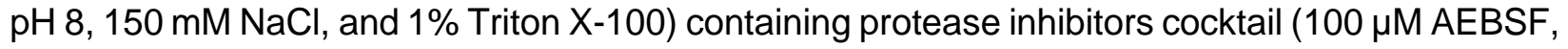
$2 \mu \mathrm{M}$ leupeptin, $80 \mathrm{nM}$ aprotinin, $5 \mu \mathrm{M}$ Bestatin, $1.5 \mu \mathrm{M}$ E-64 and $1 \mu \mathrm{M}$ pepstatin A) and phosphatase inhibitors ( $10 \mathrm{mM} \mathrm{NaF}$ and $\left.500 \mu \mathrm{M} \mathrm{Na}_{3} \mathrm{VO}_{4}\right)$ and centrifuged twice for 10 min each at 20,000 $\mathrm{xg}$ and $4{ }^{\circ} \mathrm{C}$. The supernatant was collected and total protein levels were quantified using Bradford Protein Assay. Homogenates were diluted in a mix of lysis buffer and $\beta$ mercaptoethanol containing $3 x$ loading buffer and boiled for $10 \mathrm{~min}$ at $95^{\circ} \mathrm{C}$. Aliquots containing $30-40 \mu \mathrm{g}$ total proteins were resolved by electrophoresis on a $7.5 \%$ or $10 \%$ SDS-polyacrylamide gel (SDS-PAGE) and transferred onto nitrocellulose membranes. Blots were blocked in Trisbuffered saline, $\mathrm{pH} 7.6$ containing $0.05 \%$ of Tween 20 (TBST) and $5 \%$ non-fat dry milk for $2 \mathrm{~h}$ at room temperature and then incubated overnight at $4^{\circ} \mathrm{C}$ with primary antibodies diluted 1:1000 in TBST containing $2 \%$ non-fat dry milk. Immunodetection was performed by incubating with secondary antibodies (anti-rabbit/mouse) diluted 1:5000 in TBST containing 1\% of non-fat dry milk for $1 \mathrm{~h}$. Membranes were washed in TBST and then bands were detected and quantified using SuperSignal ${ }^{\mathrm{TM}}$ West Pico PLUS Chemiluminescent Substrate using Bio-Rad chemiluminescence system as previously described $(32,51)$.

\section{Embryo sex determination for primary culture}

DNA was extracted from embryonic tissue by incubation overnight at $55^{\circ} \mathrm{C}$ in DNA lysis buffer (50 mM Tris-HCl, pH 8, $10 \mathrm{mM}$ EDTA, $20 \mathrm{mM} \mathrm{NaCl}$ and 0.031\% SDS) supplemented with 
Proteinase K. After incubation, lysates were centrifuged at $20,000 \mathrm{xg}$ for $10 \mathrm{~min}$ at $25^{\circ} \mathrm{C}$ and the supernatant was collected. DNA was precipitated by Isopropanol and was collected by centrifugation at $10,000 \mathrm{xg}$ for $10 \mathrm{~min}$ at $4^{\circ} \mathrm{C}$. Tris-EDTA buffer $(10 \mathrm{mM}$ Tris- $\mathrm{HCl}, \mathrm{pH} 8$ and $1 \mathrm{mM}$ EDTA, $\mathrm{pH}$ 8) was added to DNA, heated at $55^{\circ} \mathrm{C}$ for $10 \mathrm{~min}$ and then used for the $\mathrm{PCR}$ reaction. Primers were designed flanking an 84 bp deletion of the $\mathrm{X}$-linked Rbm31x gene relative to its $\mathrm{Y}$ linked gametolog Rbm31y (Forward; CACCTTAAGAACAAGCCAATACA and Reverse: GGCTTGTCCTGAAAACATTTGG) (33). Following the PCR reaction, products were separated on an agarose gel containing RedSafe DNA stain (FroggaBio) and visualized on Bio-Rad fluorescence system.

\section{Primary neuronal culture experiment}

Following 12-15 days incubation, cultures were starved in HBSS for $1 \mathrm{~h}$. Cells were then treated with $10 \mu \mathrm{M}$ CTEP or DMSO (vehicle for CTEP) for 30 min followed by $100 \mathrm{nM} \mathrm{A \beta}$ for $1 \mathrm{~h}$ at $37^{\circ} \mathrm{C}$. Human $\mathrm{A} \beta$ oligomers were prepared as per the manufacturer's recommendations to form the neurotoxic aggregates (52). Following this treatment, neuronal cultures were lysed with icecold RIPA buffer supplemented with protease and phosphatase inhibitors then immunoblotting was performed.

\section{Radioligand binding}

Radioligand binding was performed as previously described (53). Briefly, cells washed with PBS and ice-cold lysis buffer (10 mM Tris-HCl, $\mathrm{pH} 7.4$ and $5 \mathrm{mM}$ EDTA, pH 8.0) was used to detach the cells. Cortex from mice and human were homogenized in ice-cold lysis buffer. To prepare the crude membrane preparation, cell or brain lysates were centrifuged twice at 40,000 xg for 20 min at $4{ }^{\circ} \mathrm{C}$ and supernatant was discarded after each centrifugation and the pellets were resuspended in lysis buffer. The crude membrane preparations were then suspended in resuspension buffer (62.5 mM Tris- $\mathrm{HCl}, \mathrm{pH} 7.4$ and $1.25 \mathrm{mM}$ EDTA, pH 8.0) and kept on ice. The 
binding reactions were performed in duplicate by incubating crude membranes with $3 \mathrm{nM}\left[{ }^{3} \mathrm{H}\right]$ MPEP and increasing concentrations of either MPEP or A $\beta$ oligomers in binding buffer (62.5 mM Tris- $\mathrm{HCl}$, pH 7.4 and $1.25 \mathrm{mM}$ EDTA, pH 8.0, $200 \mathrm{mM} \mathrm{NaCl}, 6.7 \mathrm{mM} \mathrm{MgCl}, 2.5 \mathrm{mM} \mathrm{CaCl}$ and $8.33 \mathrm{mM} \mathrm{KCl}$ ) at room temperature for $90 \mathrm{~min}$. The nonspecific binding was determined using 10 $\mu \mathrm{M}$ MPEP. The binding reactions were terminated by rapid filtration through Whatman GF/C glass fiber filter sheets using semi-automated harvesting system (Brandel). The tritium-bound radioactivity was then counted using liquid scintillation counter (Beckman). The data were analyzed using GraphPad Prism, $\left[{ }^{3} \mathrm{H}\right]-$ MPEP binding as \% of maximum specific binding was calculated and the equilibrium dissociation constant $\left(K_{i}, M\right)$ of MPEP and $A \beta$ were determined.

\section{Co-immunoprecipitation}

Hippocampus from male and female wild-type and mGluR5 $^{-/-}$mice were dissected and lysed in non-denaturing lysis buffer containing protease inhibitors provided with coimmunoprecipitation kit. Lysates were rotated for 1 hour at $4{ }^{\circ} \mathrm{C}$ and centrifuged at $10,000 \mathrm{~g}$ for 10 min at $4 \stackrel{\circ}{\circ}$ to pellet insoluble material. Precleared supernatant $(500 \mu \mathrm{g})$ was incubated with 1 $\mu \mathrm{g}$ of anti-PrPC antibody over night at $4^{\circ} \mathrm{C}$. Freshly washed protein A/G-sepharose beads were added to lysate/antibody mixture and samples were rotated for 2 hours at $4{ }^{\circ} \mathrm{C}$. Beads were washed with wash buffer provided in the kit and then boiled with $3 x$ loading buffer containing $\beta$ mercaptoethanol for $10 \mathrm{~min}$ at $90^{\circ} \mathrm{C}$. Samples were separated by SDS-PAGE and immunoblotted to identify co-immunoprecipitated mGluR5. An additional immunoblot was performed to examine mGluR5 and $\mathrm{PrP}^{\mathrm{C}}$ protein expression in lysates prepared before incubation with antibody.

\section{Statistical analysis}

Means \pm SEM are shown for each of independent experiments are shown in the various figure legends. GraphPad Prism 8 was used to analyze data for normality and statistical significance. Data normality was tested using Anderson-Darling and D'Agostino-Pearson omnibus 
bioRxiv preprint doi: https://doi.org/10.1101/803262; this version posted June 10, 2020. The copyright holder for this preprint (which was not certified by peer review) is the author/funder. All rights reserved. No reuse allowed without permission.

tests and statistical significance was determined by two-way ANOVA, Student's t test or KruskalWallis test as appropriate for the significant main interactions. Statistical details of individual experiments are indicated in figure legends 


\section{REFERENCES}

1. L. Rizzi, I. Rosset, M. Roriz-Cruz, Global Epidemiology of Dementia: Alzheimer's and Vascular Types, Biomed Res. Int. 2014, 1-8 (2014).

2. D. A. Casey, D. Antimisiaris, J. O'Brien, Drugs for Alzheimer's disease: are they effective?, $P$ T35, 208-11 (2010).

3. K. L. Lanctôt, R. D. Rajaram, N. Herrmann, Therapy for Alzheimer's Disease: How Effective are Current Treatments?, Ther. Adv. Neurol. Disord. 2, 163-80 (2009).

4. S. Hunter, C. Brayne, Understanding the roles of mutations in the amyloid precursor protein in Alzheimer disease, Mol. Psychiatry (2017), doi:10.1038/mp.2017.218.

5. A. Hamilton, G. W. Zamponi, S. S. G. Ferguson, Glutamate receptors function as scaffolds for the regulation of $\beta$-amyloid and cellular prion protein signaling complexes, Mol. Brain 8, 18 (2015).

6. J. C. Polanco, C. Li, L.-G. Bodea, R. Martinez-Marmol, F. A. Meunier, J. Götz, Amyloid- $\beta$ and tau complexity — towards improved biomarkers and targeted therapies, Nat. Rev. Neurol. 14, 22-39 (2017).

7. J. L. Podcasy, C. N. Epperson, Considering sex and gender in Alzheimer disease and other dementias., Dialogues Clin. Neurosci. 18, 437-446 (2016).

8. D. W. Fisher, D. A. Bennett, H. Dong, Sexual dimorphism in predisposition to Alzheimer's disease, Neurobiol. Aging 70, 308-324 (2018).

9. R. S. Vest, C. J. Pike, Gender, sex steroid hormones, and Alzheimer's disease, Horm. Behav. 63, 301-307 (2013).

10. H. Hampel, A. Vergallo, F. S. Giorgi, S. H. Kim, H. Depypere, M. Graziani, A. Saidi, R. 
Nisticò, S. Lista, Alzheimer Precision Medicine Initiative (APMI), Precision medicine and drug development in Alzheimer's disease: the importance of sexual dimorphism and patient stratification, Front. Neuroendocrinol. 50, 31-51 (2018).

11. K. R. Laws, K. Irvine, T. M. Gale, Sex differences in cognitive impairment in Alzheimer's disease, World J. Psychiatry 6, 54 (2016).

12. Y. Tang, Z. Min, X.-J. Xiang, L. Liu, Y.-L. Ma, B.-L. Zhu, L. Song, J. Tang, X.-J. Deng, Z. Yan, G.-J. Chen, Estrogen-related receptor alpha is involved in Alzheimer's disease-like pathology, Exp. Neurol. 305, 89-96 (2018).

13. J. F. Kelly, J. L. Bienias, A. Shah, K. A. Meeke, J. A. Schneider, E. Soriano, D. A. Bennett, Levels of estrogen receptors alpha and beta in frontal cortex of patients with Alzheimer's disease: relationship to Mini-Mental State Examination scores., Curr. Alzheimer Res. 5, 45-51 (2008).

14. S. R. Rapp, M. A. Espeland, S. A. Shumaker, V. W. Henderson, R. L. Brunner, J. E. Manson, M. L. S. Gass, M. L. Stefanick, D. S. Lane, J. Hays, K. C. Johnson, L. H. Coker, M. Dailey, D. Bowen, WHIMS Investigators, Effect of estrogen plus progestin on global cognitive function in postmenopausal women: the Women's Health Initiative Memory Study: a randomized controlled trial., JAMA 289, 2663-72 (2003).

15. A. C. McCarrey, S. M. Resnick, Postmenopausal hormone therapy and cognition, Horm. Behav. 74, 167-172 (2015).

16. C. M. Niswender, P. J. Conn, Metabotropic Glutamate Receptors: Physiology, Pharmacology, and Disease, Annu. Rev. Pharmacol. Toxicol. 50, 295-322 (2010).

17. J. W. Um, A. C. Kaufman, M. Kostylev, J. K. Heiss, M. Stagi, H. Takahashi, M. E. Kerrisk, A. Vortmeyer, T. Wisniewski, A. J. Koleske, E. C. Gunther, H. B. Nygaard, S. M. Strittmatter, 
Metabotropic Glutamate Receptor 5 Is a Coreceptor for Alzheimer A $\beta$ Oligomer Bound to Cellular Prion Protein, Neuron 79, 887-902 (2013).

18. L. T. Haas, M. A. Kostylev, S. M. Strittmatter, Therapeutic molecules and endogenous ligands regulate the interaction between brain cellular prion protein (PrPC) and metabotropic glutamate receptor 5 (mGluR5), J. Biol. Chem. 289, 28460-28477 (2014).

19. M. Renner, P. N. Lacor, P. T. Velasco, J. Xu, A. Contractor, W. L. Klein, A. Triller, Deleterious effects of amyloid beta oligomers acting as an extracellular scaffold for mGluR5., Neuron 66, 739-54 (2010).

20. K. S. Abd-Elrahman, A. Hamilton, M. Vasefi, S. S. G. Ferguson, Autophagy is increased following either pharmacological or genetic silencing of mGluR5 signaling in Alzheimer's disease mouse models, Mol. Brain 11 (2018), doi:10.1186/s13041-018-0364-9.

21. A. Hamilton, J. L. Esseltine, R. A. DeVries, S. P. Cregan, S. S. G. Ferguson, Metabotropic glutamate receptor 5 knockout reduces cognitive impairment and pathogenesis in a mouse model of Alzheimer's disease., Mol. Brain 7, 40 (2014).

22. A. Hamilton, M. Vasefi, C. Vander Tuin, R. J. Mcquaid, H. Anisman, S. S. G. Ferguson, Chronic Pharmacological mGluR5 Inhibition Prevents Cognitive Impairment and Reduces Pathogenesis in an Alzheimer Disease Mouse Model, Cell Rep. 15, 1-7 (2016).

23. Y. Zhang, X. He, X. Wu, M. Lei, Z. Wei, X. Zhang, L. Wen, P. Xu, S. Li, S. Qu, Rapamycin upregulates glutamate transporter and IL-6 expression in astrocytes in a mouse model of Parkinson's disease, Cell Death Dis. 8, e2611-e2611 (2017).

24. K. S. Abd-Elrahman, A. Hamilton, A. Albaker, S. S. G. Ferguson, mGluR5 Contribution to Neuropathology in Alzheimer Mice Is Disease Stage-Dependent, ACS Pharmacol. Transl. Sci. 3, 334-344 (2020). 
25. L. T. Haas, S. V. Salazar, L. M. Smith, H. R. Zhao, T. O. Cox, C. S. Herber, A. P. Degnan, A. Balakrishnan, J. E. Macor, C. F. Albright, S. M. Strittmatter, Silent Allosteric Modulation of mGluR5 Maintains Glutamate Signaling while Rescuing Alzheimer's Mouse Phenotypes, Cell Rep. 20, 76-88 (2017).

26. P. M. Q. Bellozi, G. F. Gomes, M. C. M. da Silva, I. V. de A. Lima, C. R. Á. Batista, W. de O. Carneiro Junior, J. G. Dória, É. L. M. Vieira, R. P. Vieira, R. P. de Freitas, C. N. Ferreira, E. Candelario-Jalil, T. Wyss-Coray, F. M. Ribeiro, A. C. P. de Oliveira, A positive allosteric modulator of mGluR5 promotes neuroprotective effects in mouse models of Alzheimer's disease, Neuropharmacology 160 (2019), doi:10.1016/j.neuropharm.2019.107785.

27. L. Lindemann, G. Jaeschke, A. Michalon, E. Vieira, M. Honer, W. Spooren, R. Porter, T. Hartung, S. Kolczewski, B. Büttelmann, C. Flament, C. Diener, C. Fischer, S. Gatti, E. P. Prinssen, N. Parrott, G. Hoffmann, J. G. Wettstein, CTEP: a novel, potent, long-acting, and orally bioavailable metabotropic glutamate receptor 5 inhibitor., J. Pharmacol. Exp. Ther. 339, 474-86 (2011).

28. J. L. Jankowsky, D. J. Fadale, J. Anderson, G. M. Xu, V. Gonzales, N. A. Jenkins, N. G. Copeland, M. K. Lee, L. H. Younkin, S. L. Wagner, S. G. Younkin, D. R. Borchelt, Mutant presenilins specifically elevate the levels of the 42 residue beta-amyloid peptide in vivo: evidence for augmentation of a 42-specific gamma secretase., Hum. Mol. Genet. 13, 159-70 (2004).

29. N.-W. Hu, A. J. Nicoll, D. Zhang, A. J. Mably, T. O’Malley, S. A. Purro, C. Terry, J. Collinge, D. M. Walsh, M. J. Rowan, mGlu5 receptors and cellular prion protein mediate amyloid- $\beta$ facilitated synaptic long-term depression in vivo., Nat. Commun. 5, 3374 (2014).

30. L. T. Haas, S. M. Strittmatter, Oligomers of amyloid prevent physiological activation of the cellular prion protein-metabotropic glutamate receptor 5 complex by glutamate in Alzheimer 
disease, J. Biol. Chem. 291, 17112-17121 (2016).

31. F. H. Beraldo, V. G. Ostapchenko, F. A. Caetano, A. L. S. Guimaraes, G. D. S. Ferretti, N. Daude, L. Bertram, K. O. P. C. Nogueira, J. L. Silva, D. Westaway, N. R. Cashman, V. R. Martins, V. F. Prado, M. A. M. Prado, Regulation of amyloid $\beta$ oligomer binding to neurons and neurotoxicity by the prion protein-mGluR5 complex, J. Biol. Chem. 291, 21945-21955 (2016).

32. K. S. Abd-Elrahman, A. Hamilton, S. R. Hutchinson, F. Liu, R. C. Russell, S. S. G. Ferguson, mGluR5 antagonism increases autophagy and prevents disease progression in the $z Q 175$ mouse model of Huntington's disease, Sci. Signal. 10, eaan6387 (2017).

33. S. J. Tunster, Genetic sex determination of mice by simplex PCR., Biol. Sex Differ. 8, 31 (2017).

34. L. Ruan, Z. Kang, G. Pei, Y. Le, Amyloid deposition and inflammation in APPswe/PS1dE9 mouse model of Alzheimer's disease., Curr. Alzheimer Res. 6, 531-40 (2009).

35. T. Zhang, K. Dong, W. Liang, D. Xu, H. Xia, J. Geng, A. Najafov, M. Liu, Y. Li, X. Han, J. Xiao, Z. Jin, T. Peng, Y. Gao, Y. Cai, C. Qi, Q. Zhang, A. Sun, M. Lipinski, H. Zhu, Y. Xiong, P. P. Pandolfi, H. Li, Q. Yu, J. Yuan, G-protein-coupled receptors regulate autophagy by ZBTB16mediated ubiquitination and proteasomal degradation of Atg14L., Elife 4, e06734 (2015).

36. P. A. Insel, C.-M. Tang, I. Hahntow, M. C. Michel, Impact of GPCRs in clinical medicine: Monogenic diseases, genetic variants and drug targets, Biochim. Biophys. Acta - Biomembr. 1768, 994-1005 (2007).

37. F. Raka, A. R. Di Sebastiano, S. C. Kulhawy, F. M. Ribeiro, C. M. Godin, F. A. Caetano, S. Angers, S. S. G. Ferguson, Ca2+/Calmodulin-dependent protein Kinase II interacts with group i Metabotropic Glutamate and facilitates Receptor Endocytosis and ERK1/2 signaling: Role of $\beta$ Amyloid, Mol. Brain 8, 21 (2015). 
38. L. T. Haas, S. V Salazar, M. A. Kostylev, J. W. Um, A. C. Kaufman, S. M. Strittmatter, Metabotropic glutamate receptor 5 couples cellular prion protein to intracellular signalling in Alzheimer's disease., Brain 139, 526-46 (2016).

39. R. J. O'Brien, P. C. Wong, Amyloid precursor protein processing and Alzheimer's disease., Annu. Rev. Neurosci. 34, 185-204 (2011).

40. J. Nah, J. Yuan, Y.-K. Jung, Autophagy in neurodegenerative diseases: from mechanism to therapeutic approach., Mol. Cells 38, 381-9 (2015).

41. R. A. Nixon, The role of autophagy in neurodegenerative disease, Nat. Med. 19, 983-997 (2013).

42. Q. Li, Y. Liu, M. Sun, Autophagy and Alzheimer's Disease, Cell. Mol. Neurobiol. 37, 377-388 (2017).

43. M. E. Orr, S. Oddo, Autophagic/lysosomal dysfunction in Alzheimer's disease, Alzheimers. Res. Ther. 5, 53 (2013).

44. D. C. Rubinsztein, M. DiFiglia, N. Heintz, R. A. Nixon, Z.-H. Qin, B. Ravikumar, L. Stefanis, A. Tolkovsky, Autophagy and its possible roles in nervous system diseases, damage and repair., Autophagy 1, 11-22 (2005).

45. J. A. Quiroz, P. Tamburri, D. Deptula, L. Banken, U. Beyer, M. Rabbia, N. Parkar, P. Fontoura, L. Santarelli, Efficacy and Safety of Basimglurant as Adjunctive Therapy for Major Depression, JAMA Psychiatry 73, 675 (2016).

46. E. A. Youssef, E. Berry-Kravis, C. Czech, R. J. Hagerman, D. Hessl, C. Y. Wong, M. Rabbia, D. Deptula, A. John, R. Kinch, P. Drewitt, L. Lindemann, M. Marcinowski, R. Langland, C. Horn, P. Fontoura, L. Santarelli, J. A. Quiroz, Effect of the mGluR5-NAM Basimglurant on Behavior in Adolescents and Adults with Fragile X Syndrome in a Randomized, Double-Blind, Placebo- 
Controlled Trial: FragXis Phase 2 Results, Neuropsychopharmacology 43, 503-512 (2018).

47. H. A. Dunn, C. Orlandi, K. A. Martemyanov, Beyond the ligand: Extracellular and transcellular G protein-coupled receptor complexes in physiology and pharmacology, Pharmacol. Rev. 71, 503-519 (2019).

48. G. F. Chen, T. H. Xu, Y. Yan, Y. R. Zhou, Y. Jiang, K. Melcher, H. E. Xu, Amyloid beta: Structure, biology and structure-based therapeutic developmentActa Pharmacol. Sin. 38, 12051235 (2017).

49. T. M. Piers, D. H. Kim, B. C. Kim, P. Regan, D. J. Whitcomb, K. Cho, Translational concepts of mglur5 in synaptic diseases of the brain, Front. Pharmacol. 3 NOV, 199 (2012).

50. C. A. Schneider, W. S. Rasband, K. W. Eliceiri, NIH Image to ImageJ: 25 years of image analysisNat. Methods 9, 671-675 (2012).

51. K. Farmer, K. S. Abd-Elrahman, A. Derksen, E. M. Rowe, A. M. Thompson, C. A. Rudyk, N. A. Prowse, Z. Dwyer, S. C. Bureau, T. Fortin, S. S. G. Ferguson, S. Hayley, mGluR5 Allosteric Modulation Promotes Neurorecovery in a 6-OHDA-Toxicant Model of Parkinson's Disease, Mol. Neurobiol. , 1-14 (2019).

52. L. K. Simmons, P. C. May, K. J. Tomaselli, R. E. Rydel, K. S. Fuson, E. F. Brigham, S. Wright, I. Lieberburg, G. W. Becker, D. N. Brems, W. Y. Li, Secondary structure of amyloid $\beta$ peptide correlates with neurotoxic activity in vitro, Mol. Pharmacol. 45, 373-379 (1994).

53. B. Plouffe, M. Tiberi, Functional analysis of human D1 and D5 dopaminergic G proteincoupled receptors: Lessons from mutagenesis of a conserved serine residue in the cytosolic end of transmembrane region 6, Methods Mol. Biol. 964, 141-180 (2013). 


\section{ACKNOWLEDGMENTS}

S.S.G.F is a Tier I Canada Research Chair in Brain and Mind. K.S.A is a Lecturer at the Department of Pharmacology and Toxicology, Faculty of Pharmacy, Alexandria University. Thanks to Shaunessy Hutchinson for breeding the mouse colony, the Behavior and Physiology core at the University of Ottawa, Bassam Albraidy for technical assistance, Dr. Suzette Priola (NIH) for providing CF10 cells, Dr. Andrew West (Duke University), Dr. Jennifer Chan (University Calgary) and Dr. John Woulfe (The Ottawa Hospital) for their assistance in procuring human tissues.

\section{FUNDING}

This study was supported by Canadian Institutes for Health Research (CIHR) grants (PJT-148656 and PJT-165967) and Funding from Krembil Foundation to S.S.G.F, and a Clinician Postdoctoral Fellowship from the Alberta Innovates Health Solutions (AIHS) and CIHR to K.S.A.

\section{AUTHOR CONTRIBUTIONS}

Conceptualization, K.S.A., A.H. and S.S.G.F; Methodology, Formal analysis and investigation, K.S.A., A.A., J.M.D. and A.H.; Resources, F.M.R., M.G.S., M.T., S.S.G.F.; Writing-Original draft, K.S.A.; Writing-Review \& Editing, K.S.A., S.S.G.F.; Supervision and Funding acquisition, S.S.G.F.

\section{COMPETING INTERESTS}

Authors declare no conflict of interest.

\section{DATA AND MATERIALS AVAILABILITY}

The published article includes all datasets generated and analyzed during this study. 
Table 1: Maximum specific binding and calculated $K_{i}$ for MPEP and $A \beta$ oligomers in mouse and human male and female membrane preparations.

\begin{tabular}{|c|c|c|c|c|c|}
\hline & & \multicolumn{2}{|c|}{ Male } & \multicolumn{2}{|c|}{ Female } \\
\hline & & $\begin{array}{l}\text { Max. binding } \\
\text { (DPM) }\end{array}$ & Ki (M) & $\begin{array}{l}\text { Max. binding } \\
\text { (DPM) }\end{array}$ & Ki (M) \\
\hline \multirow{2}{*}{$\begin{array}{l}\text { Mouse } \\
\text { Cortex }\end{array}$} & MPEP & $6953 \pm 156.3$ & $4.18 \mathrm{E}-08 \pm 1.48 \mathrm{E}-08$ & $6837 \pm 129.3$ & $2.27 \mathrm{E}-08 \pm 7.15 \mathrm{E}-09$ \\
\hline & $A \beta$ & $6257 \pm 479.1$ & $8.46 \mathrm{E}-11 \pm 4.49 \mathrm{E}-11$ & $9601 \pm 218.5$ & ND \\
\hline \multirow{2}{*}{$\begin{array}{c}\text { Mouse } \\
\text { Hippocampus }\end{array}$} & MPEP & $6872 \pm 313.1$ & $7.91 \mathrm{E}-09 \pm 6.86 \mathrm{E}-09$ & $6345 \pm 166.5$ & $9.18 \mathrm{E}-09 \pm 5.74 \mathrm{E}-10$ \\
\hline & $A \beta$ & $7640 \pm 307.8$ & $6.02 \mathrm{E}-11 \pm 5.05 \mathrm{E}-12$ & $8872 \pm 352.4$ & ND \\
\hline \multirow{2}{*}{$\begin{array}{l}\text { Human } \\
\text { Cortex }\end{array}$} & MPEP & $5709 \pm 116.3$ & $9.60 \mathrm{E}-09 \pm 6.57 \mathrm{E}-09$ & $8003 \pm 259.8$ & $5.04 \mathrm{E}-09 \pm 2.26 \mathrm{E}-09$ \\
\hline & $A \beta$ & $6090 \pm 102.5$ & $9.78 \mathrm{E}-11 \pm 5.75 \mathrm{E}-11$ & $8025 \pm 203.6$ & ND \\
\hline
\end{tabular}

$\mathrm{K}_{\mathrm{i}}$ : Equilibrium dissociation constant; DPM: Disintegrations per minute

\section{FIGURE LEGENDS}

Figure 1: Sex-specific binding of $A \beta$ oligomers to mGluR5 in mouse brain

$\left[{ }^{3} \mathrm{H}\right]-M P E P$ displacement curves for MPEP and A $\beta$ oligomers in membrane preparations from wild type (A) male mouse cortex, (B) female mouse cortex, (C) male mouse hippocampus and (D) female mouse hippocampus. Each binding curve represents the mean \pm SEM of 3-4 independent duplicate experiments.

Figure 2: Sex-specific interaction of $\operatorname{PrP}^{\mathrm{C}}$ with mGluR5 in mouse hippocampus

$\left[{ }^{3} \mathrm{H}\right]-M P E P$ displacement curves for MPEP and $A \beta$ oligomers in membrane preparations from CF10 cells transfected with (A) FLAG-mGluR5 or with (B) FLAG-mGluR5 + PrPC . Each binding curve represents the mean \pm SEM of 3 independent duplicate experiments. (C) Representative immunoblot (IB) and quantification of mGluR5 co-immunoprecipitated with $\mathrm{PrP}^{\mathrm{C}}$ (IP) from male and female wild-type (Wt) hippocampus with corresponding lysates. Hippocampal tissue from male and female mGluR $^{-/-}$or Wt mice in the absence of $\mathrm{PrP}^{\mathrm{C}}$ antibody (no Ab) served as a negative control ( $\mathrm{n}=6)$. Immunoprecipitation was calculated relative no Ab lane of each sex. 
Figure 3: Sex-specific binding of A $\beta$ oligomers to mGluR5 in human brain

$\left[{ }^{3} \mathrm{H}\right]-M P E P$ displacement curves for MPEP and $A \beta$ oligomers in membrane preparations from (A) male human cortex, (B) female human cortex. Each binding curve represents the mean \pm SEM of 4-5 independent duplicate experiments.

Figure 4: Sex-specific $A \beta$ oligomer-mediated activation of mGluR5 signaling in neuronal cultures

(A) Representative gel for the Rbm31 gene PCR amplicon in male and female E18 wild-type (Wt) mouse embryos. (B) Representative immunoblots and quantification of pS9-GSK3 $\beta$, ZBTB16 and p62 normalized to loading controls or total protein and expressed as a fraction of the untreated male cultures in primary cultured cortical neurons from male and female Wt E18 embryos stimulated with $A \beta$ oligomers (100 nM) in the absence (DMSO) or presence of CTEP (10 $\mu M)$. Data represents mean \pm SEM ( $n=4$ for each group). ${ }^{*} P<0.05$ versus untreated male cultures assessed by two-way ANOVA and Fisher's LSD comparisons.

Figure 5: CTEP activates autophagy and reduces $A \beta$ pathology in male, but not female, APP mice.

Representative immunoblots and quantification of (A) pS9-GSK3ß, (B) ZBTB16, (C) ATG14 and (D) p62 with the corresponding loading controls or total protein, (E) representative images of $A \beta$ staining and (F) plaque density in cortical and hippocampal brain slices quantified of 5 different $900 \mu \mathrm{m}^{2}$ regions from 6 brain slices per mouse (scale bar $=1 \mathrm{~mm}$ ), and (G) A $\beta$ oligomer concentrations $(\mathrm{pg} / \mathrm{mg})$ in 6 month old male and female wild-type (Wt) and APP mice treated with vehicle or CTEP ( $2 \mathrm{mg} / \mathrm{kg}$ ) for 12 weeks. Data represents mean \pm SEM ( $\mathrm{n}=5$ for each group) and quantification in (A-D) is expressed as a fraction of the vehicle-treated male Wt. ${ }^{*} \mathrm{P}<0.05$ vs vehicle-treated male Wt values assessed by two-way ANOVA and Fisher's LSD comparisons (B- 
D and G) or Kruskal-Wallis test $(\mathbf{A})$. ${ }^{*} \mathrm{P}<0.05$ vs vehicle-treated same sex APP assessed by Student's t-test (F).

Figure 6: CTEP improves recognition scores in male, but not female, APP mice.

Recognition index, for exploring one novel object versus familiar object in the second day of novel object recognition test following 12 week treatment with vehicle or CTEP $(2 \mathrm{mg} / \mathrm{kg})$ of 6 month old (A) male (B) female wild-type (Wt) and APP mice. Data represents mean \pm SEM $(n=8-10$ for each group). * $\mathrm{P}<0.05$ versus familiar object assessed by two-way ANOVA and Fisher's LSD comparisons. Mice were excluded from analysis due to spontaneous death

Figure 7: CTEP treatment improves performance of male, but not female, APP mice in MWM and RMWM.

Escape latency and time spent in the target quadrant for MWM (A and B) and RMWM (C and D) in 6 month old male and female wild-type (Wt) and APP mice following 12 week treatment with either vehicle or CTEP $(2 \mathrm{mg} / \mathrm{kg})$. Data represents mean \pm SEM $\left(\mathrm{n}=8-10\right.$ for each group). ${ }^{*} \mathrm{P}<0.05$ vs vehicle-treated Wt assessed by two-way ANOVA and Fisher's LSD comparisons. Mice excluded from analysis were due to spontaneous death.

Figure 8: Schematic representation depicting $A \beta$ oligomer induced sex-selective pathophysiological mGluR5 signaling

$\mathrm{PrP}^{\mathrm{C}}$ forms a scaffolding complex with male mGluR5 and $\mathrm{A} \beta$ oligomers and elicit the inactivation of ZBTB16-mediated autophagy. The reduction in autophagic clearance of A $\beta$ oligomers triggers pathological signaling and results in cognitive deficits. In female brain, lack on interaction between $\mathrm{PrP}^{\mathrm{C}}$ and mGluR5 prevents the formation of $\mathrm{mGluR5/A \beta}$ oligomer/PrP ${ }^{\mathrm{C}}$ complex and therefore pathological signaling and cognitive deficits are likely mediated by mechanism(s) other than mGluR5. 


\section{Figure 1}
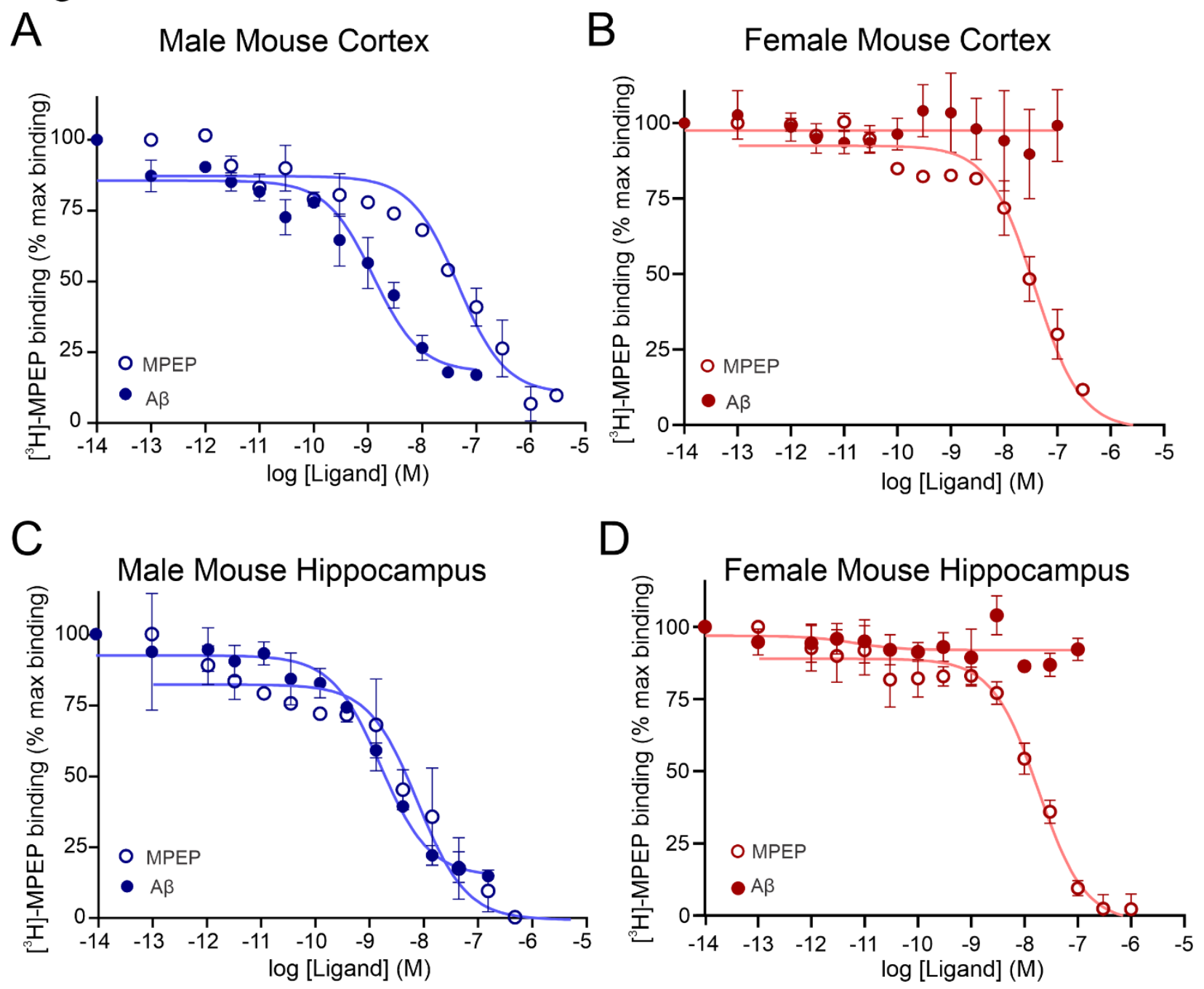


\section{Figure 2}
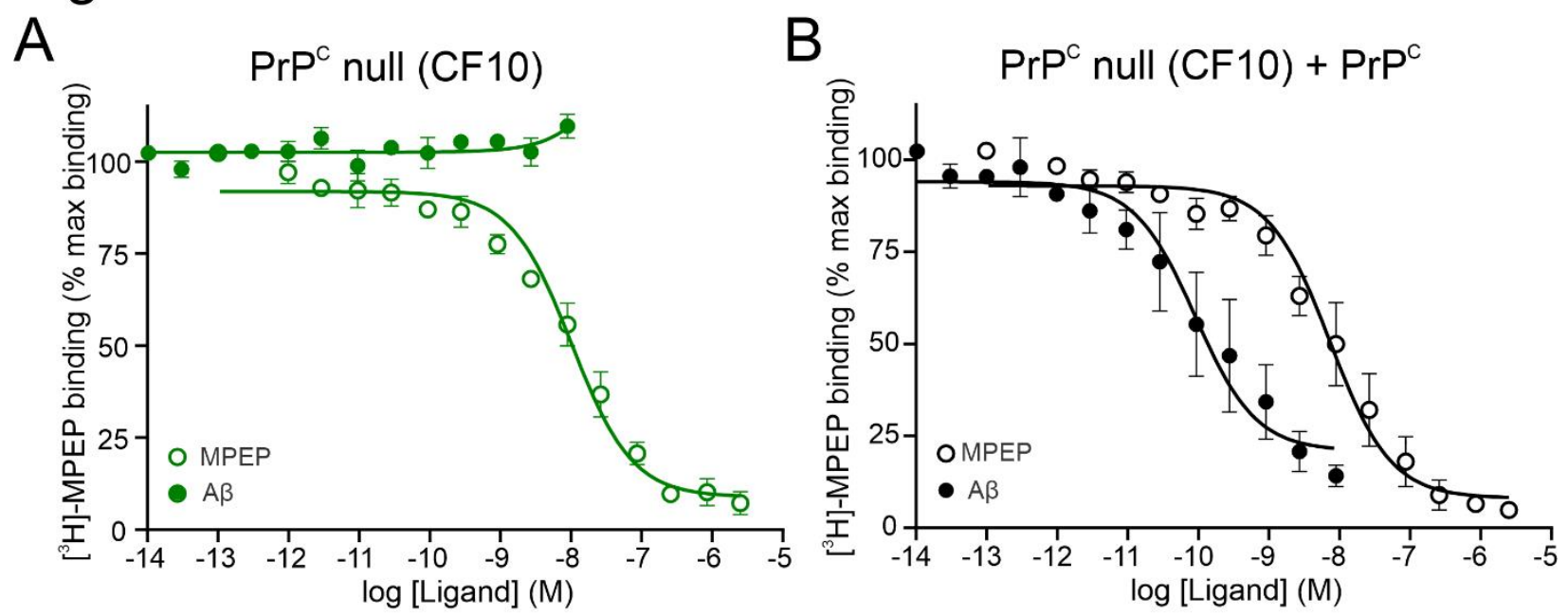

C

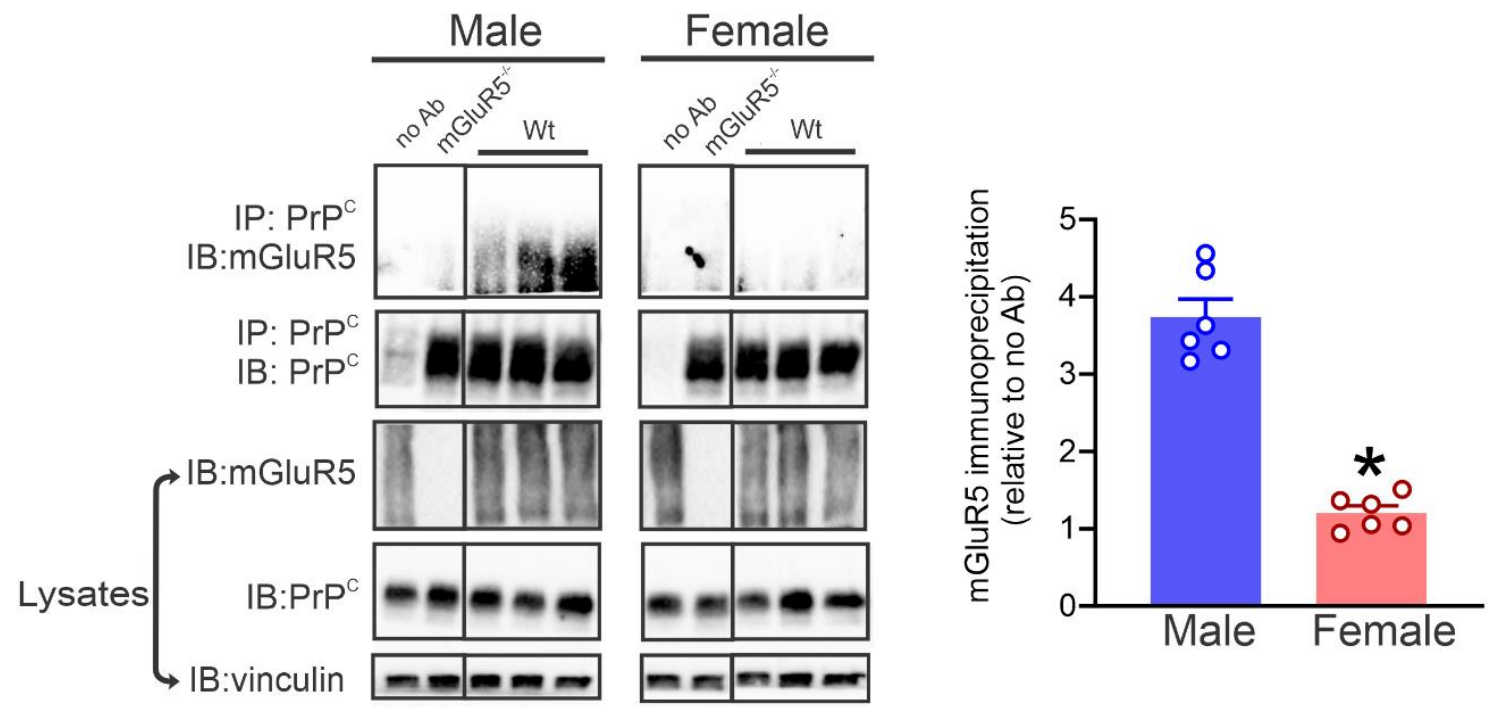




\section{Figure 3}
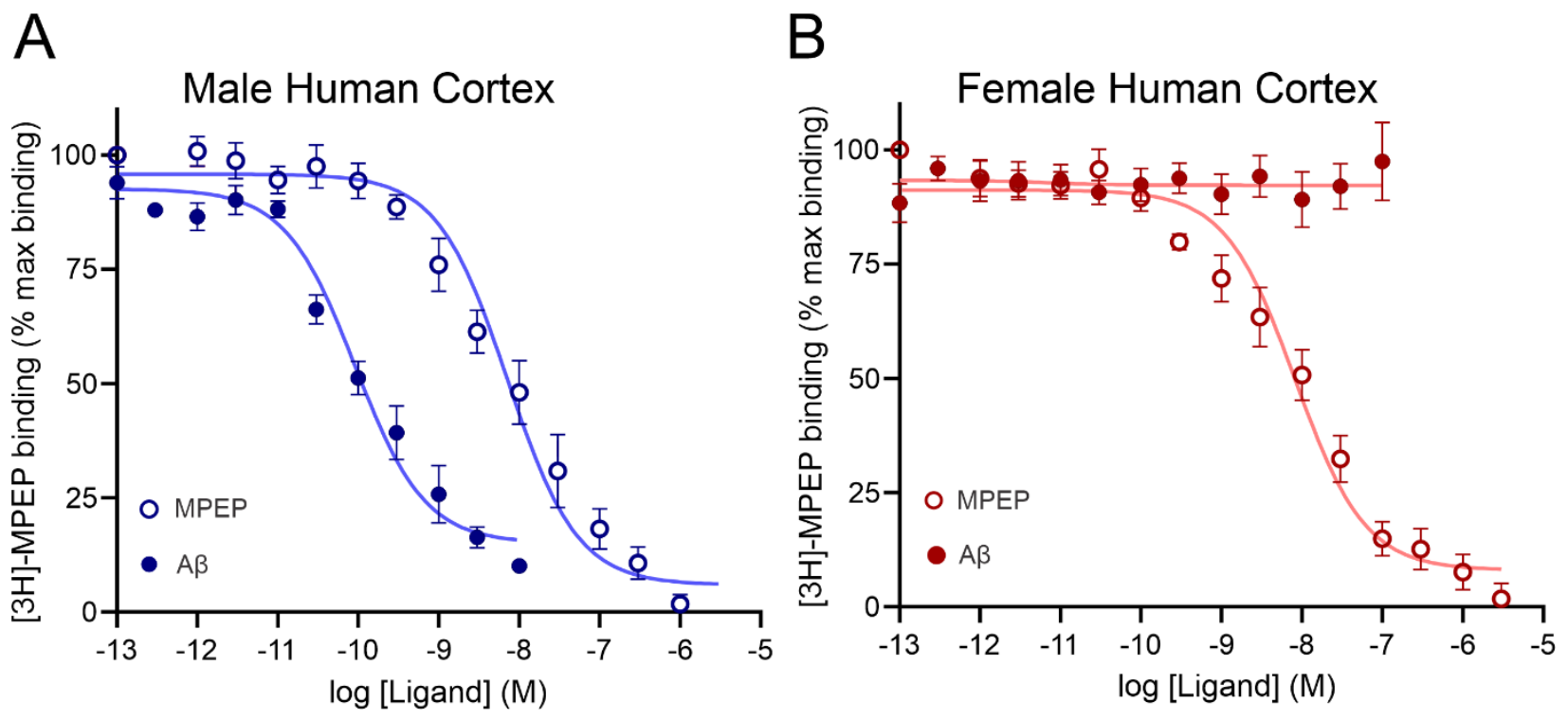


\section{Figure 4}
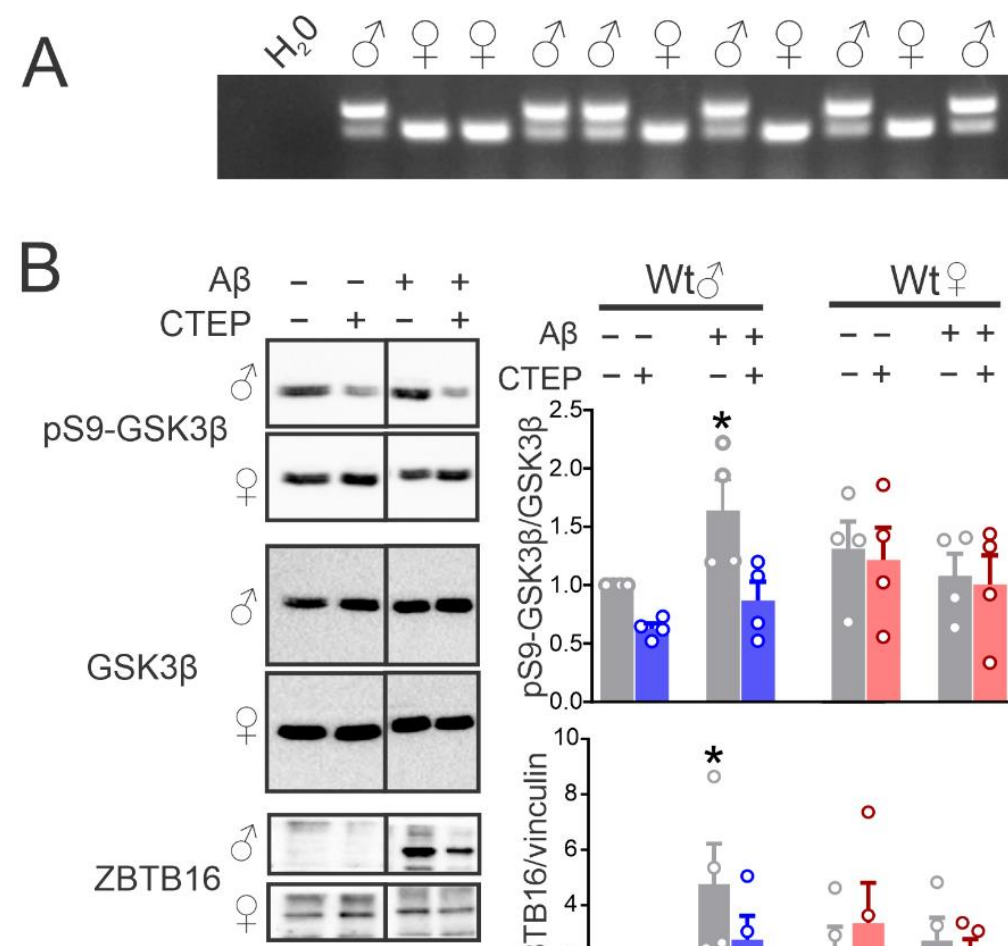

P62

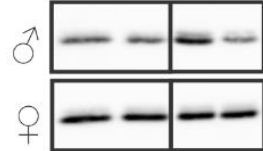

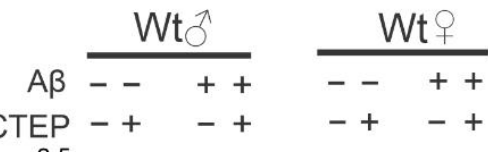

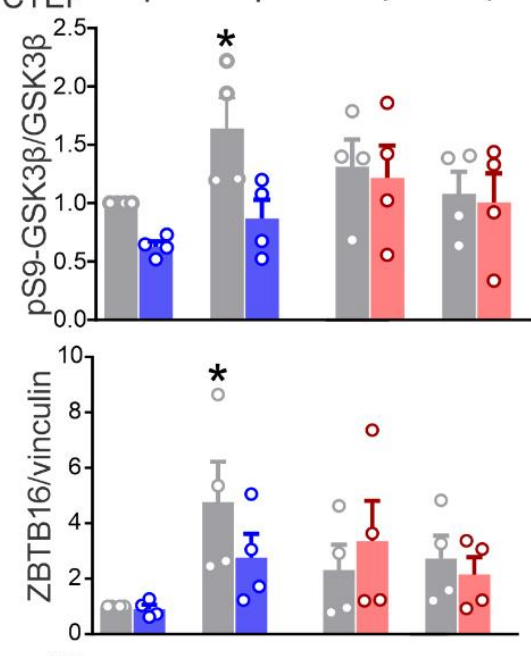

Vinculin
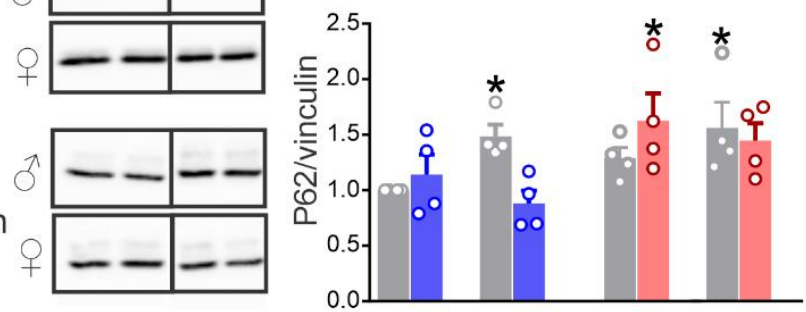


\section{Figure 5}

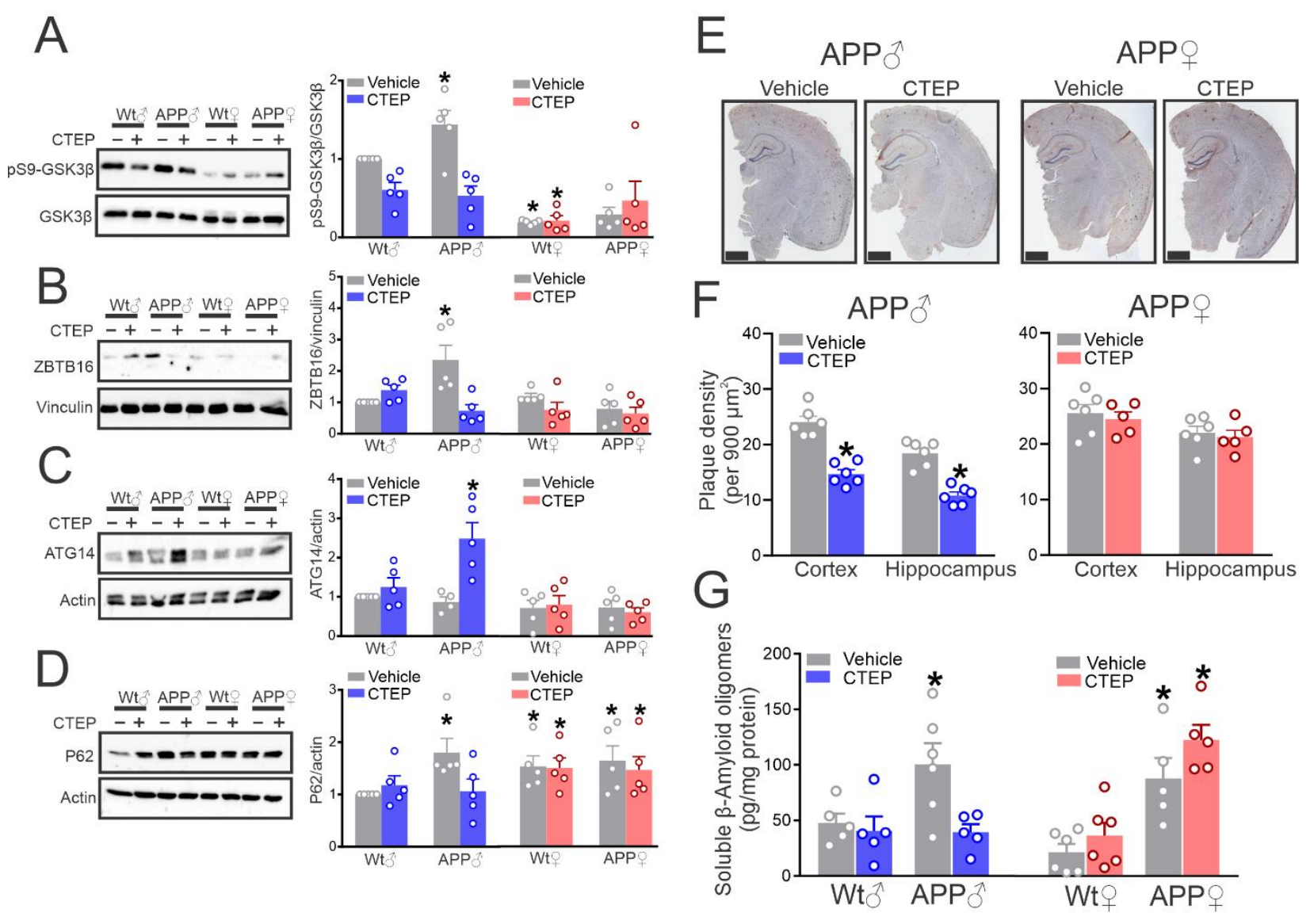




\section{Figure 6}
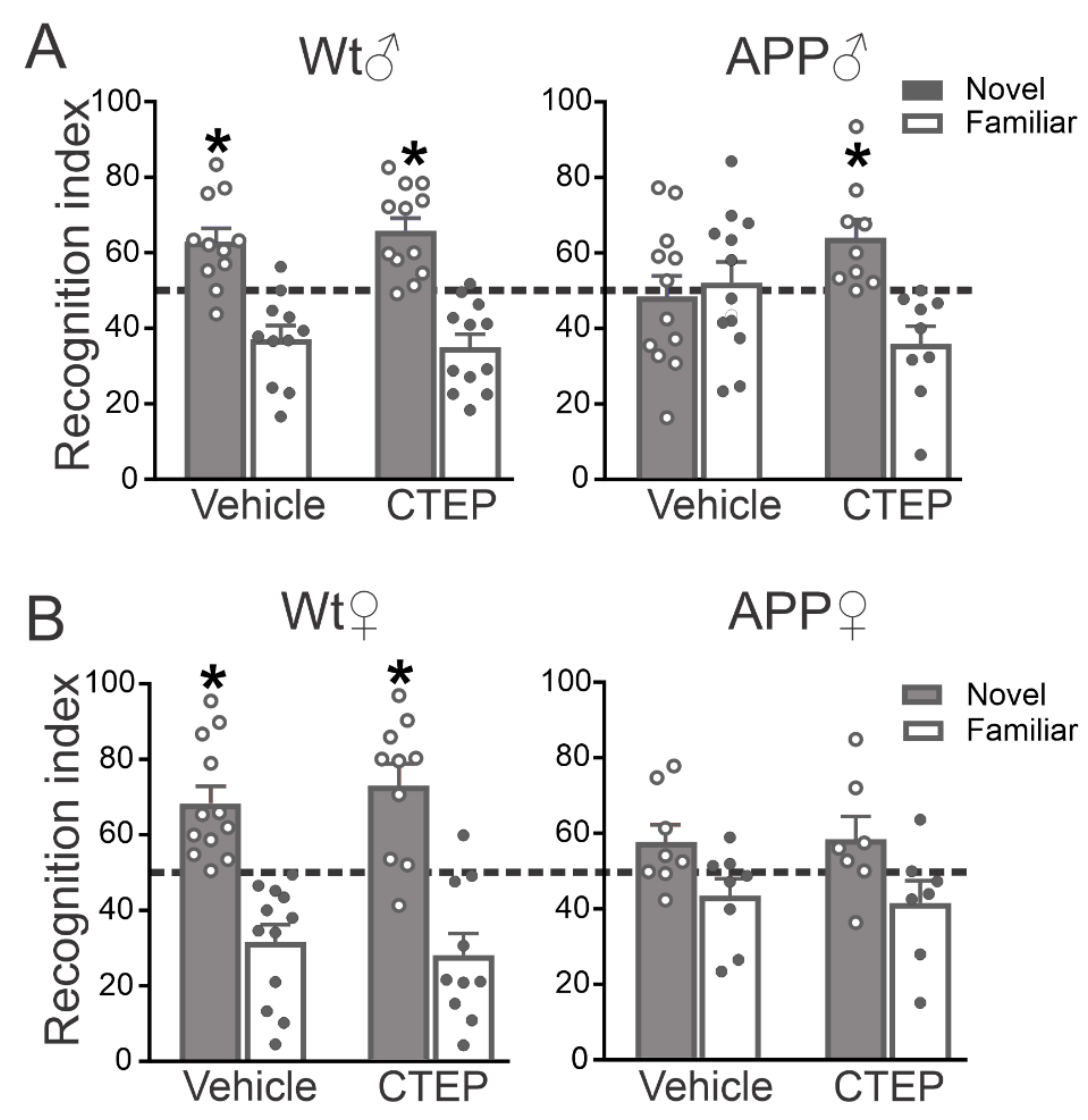


\section{Figure 7}

A

MWM
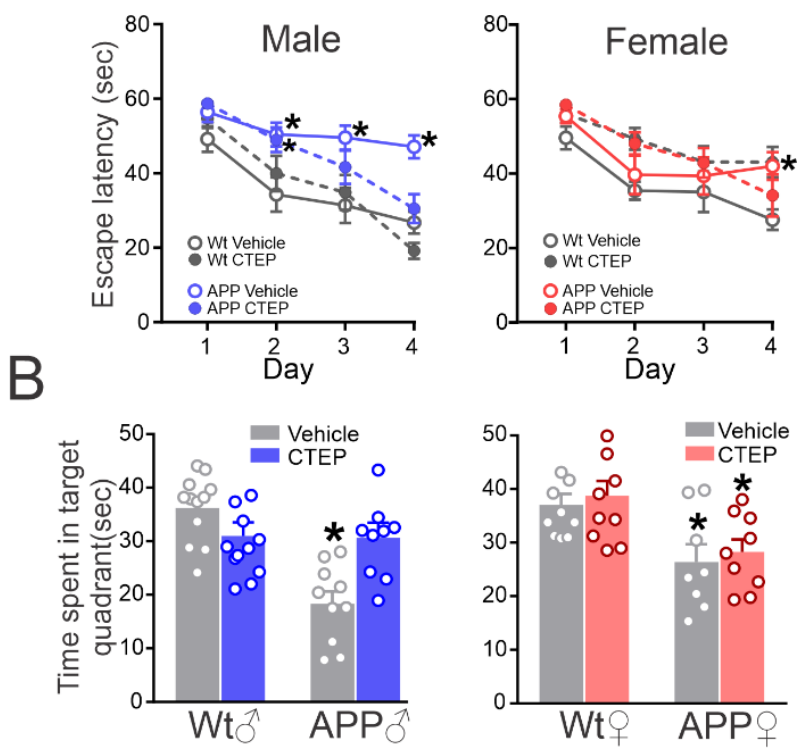

C

RMWM
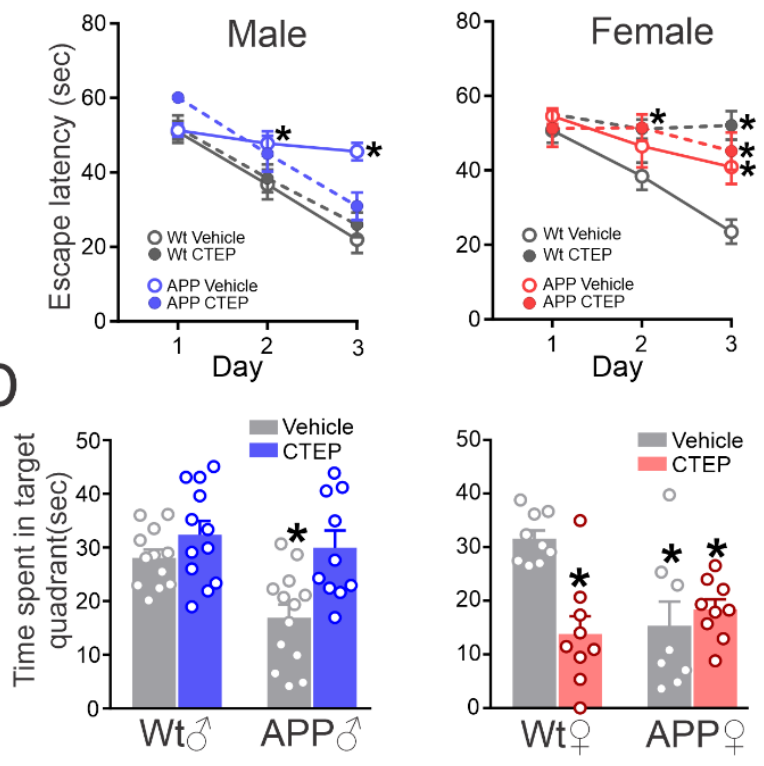


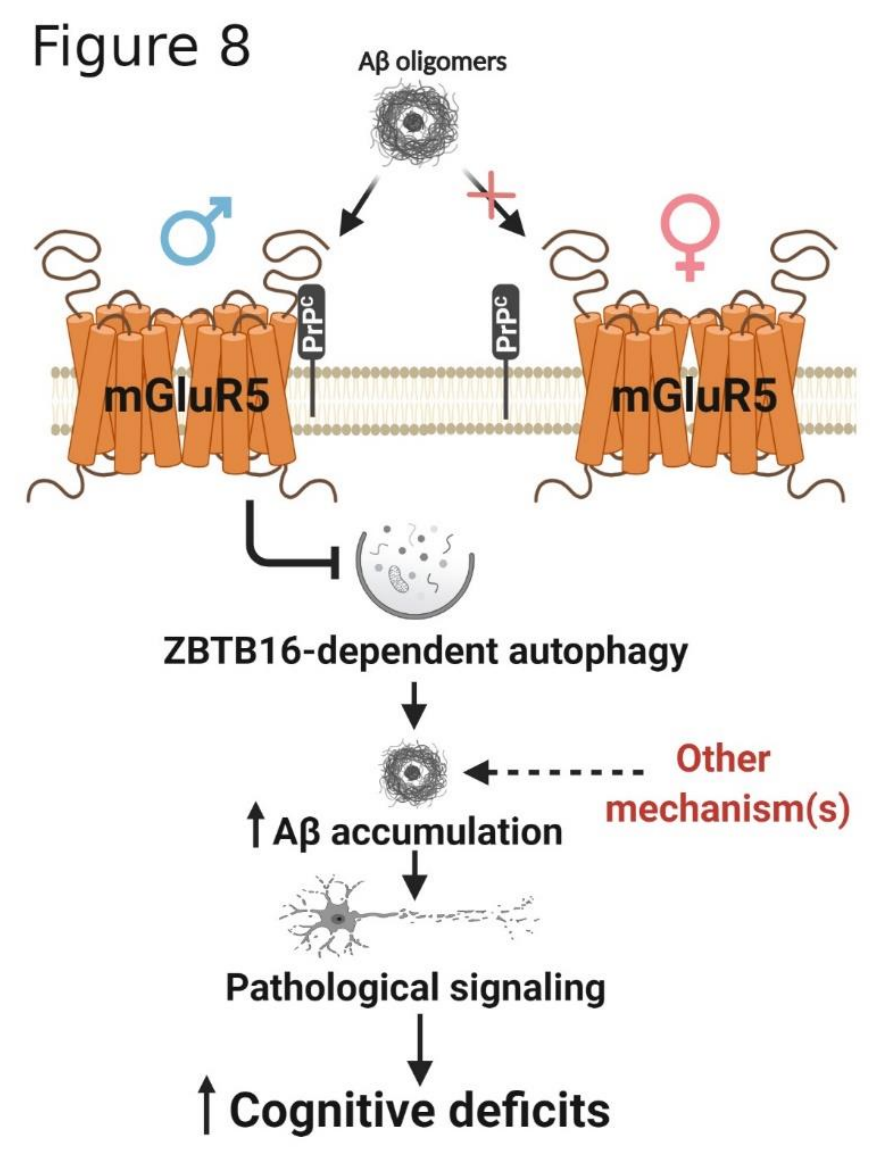

